\title{
Inter-basin water transfer effects on the invertebrates of the Mvuzane River: A test of the SASS rapid biomonitoring protocol to assess the impact of flow modification
}

\author{
SP Weerts ${ }^{1,2 *}$ and DP Cyrus ${ }^{1}$ \\ ${ }^{1}$ Coastal Research Unit of Zululand, University of Zululand, Private Bag X1001, KwaDlangezwa 3886, South Africa \\ ${ }^{2}$ CSIR, Natural Resources \& the Environment, PO Box 17001, Congella 4013, South Africa
}

\begin{abstract}
Effects of the transfer of water from the Thukela to the Mvuzane River were investigated using the SASS rapid bioassessment technique and more quantitative methods of guild composition and community analyses. Although the transfer was relatively small $\left(<1 \mathrm{~m}^{3} / \mathrm{s}\right)$ it completely dominated natural flows in the recipient system. SASS monitoring was found to be useful as a rapid, field-based assessment of water quality and can be used to act as a 'red flag' to problems in the future. However, it was not sensitive to changes in the community structure at different sites and was inefficient as a tool to investigate the wider ecological impacts of the transfer scheme, most notably those associated with flow modification. Changes in the invertebrate fauna were most easily explained in terms of the effect of increased flow velocities and volumes on taxa that were classified as 'swimmers' and 'skaters'. Impacts via disruption to trophic pathways cannot be discounted and will most certainly occur with prolonged water transfer.
\end{abstract}

\section{Introduction}

Increasing water demands of mining, industrial, agricultural and domestic users in the greater Richards Bay - Empangeni area have largely been met by the Goedertrouw Dam, which was completed in 1980. Controlled releases from this dam, down the lower course of the Mhlathuze, are extracted from the river and pumped into the coastal lake Nsezi, which is used as a balancing reservoir. The necessity to assure this supply of water, and increase it in the future, has long been recognised by the region's principal bulk water operator (Mhlathuze Water Amanzi) and the feasibility of augmentation by inter-basin water transfer (IBT) has been under investigation since the early 1990s. To this end a scheme was commissioned to pump water from the Thukela River at Middledrift into the headwaters of the Mvuzane River, a small tributary of the Mhlathuze above the Goedertrouw Dam (Fig. 1). The first phase has been completed and has a pumping capacity of $1.2 \mathrm{~m}^{3} / \mathrm{s}$ (two pump trains with a pump capacity of $0.6 \mathrm{~m}^{3} / \mathrm{s}$ each).

No work had been done on the impact of this transfer scheme on the receiving river and the need for baseline data on critical environmental indicators was recognised. The Coastal Research Unit of Zululand (CRUZ) was commissioned to investigate, and provide baseline data on the biota of the Mvuzane River. Changes in the biota after the implementation of full operation of the scheme could then be gauged using these baseline data. A modified version of the South African Scoring System Version 4 (SASS4; Chutter, 1998), based on aquatic invertebrates, was chosen as a biomonitoring tool for this project. The SASS protocol has been widely accepted in South Africa as a method of rapid biological assessment and indicator of river health and water quality. It is a useful biomonitoring instrument in that it allows rapid sampling, and processing of the sample, to attain a univariate index that can be understood not only by biologists, but also by managers, decision-makers and the general public.

\footnotetext{
* To whom all correspondence should be addressed.

Im +27 31 242-2356; fax: +27 31 261-2509;

e-mail: sweerts@csir.co.za

Received 30 August 2001; accepted in revised form 10 January 2008
}

SASS is also used extensively in the determination of ecological reserves for Instream Flow Requirement (IFR) studies as required by the National Water Act (No 36 of 1998). In the currently accepted methodology SASS metrics are used to define Reference Conditions and Present Ecological State (PES) and therefore by play an important role in the determination of the Ecological Reserve Category (ERC).

Unfortunately fieldwork for this survey was only commissioned and conducted five months after trial pumping of water from the Thukela had already commenced. Transfer discharges never exceeded $1 \mathrm{~m}^{3} / \mathrm{s}$ but when the river was first sampled in September 1999 it was during conditions of unnaturally high flow due to transfer pumping. The faunal assemblage sampled at this time was therefore already influenced by the IBT. However, an opportunity to sample natural flow conditions was presented in 2000 when, by mid-October, no water had been pumped from the Thukela for nearly 10 months. These data were considered to be more representative of the baseline state of the Mvuzane River, although the possibility of lasting impacts from the previous year's extreme flows could not be discounted.

By applying a variety of techniques of data analysis, this study provided the opportunity to comment on the impact of elevated flows on the invertebrate biota of a small subtropical river in an upper foothills reach and evaluate the efficiency of a rapid biological assessment technique (SASS) in detecting such impact.

\section{Study area}

The Mvuzane River is a tributary of the Mhlathuze River above the Goedertrouw Dam (Fig. 1). It rises at approximately 1000 $\mathrm{m}$ in the foothills near Eshowe, northern KwaZulu-Natal, and runs a course of about $35 \mathrm{~km}$ before its confluence with the Mhlathuze River at an altitude of $380 \mathrm{~m}$. Land along the length of the river is under tribal tenure and there is no industry in the catchment. Water is used for subsistence purposes, including drinking, cooking, washing, bucket irrigation and livestock watering. Riverine resources from the banks and floodplain are also exploited with gathering of firewood and building material, and grazing of livestock common forms of utilisation. As a 

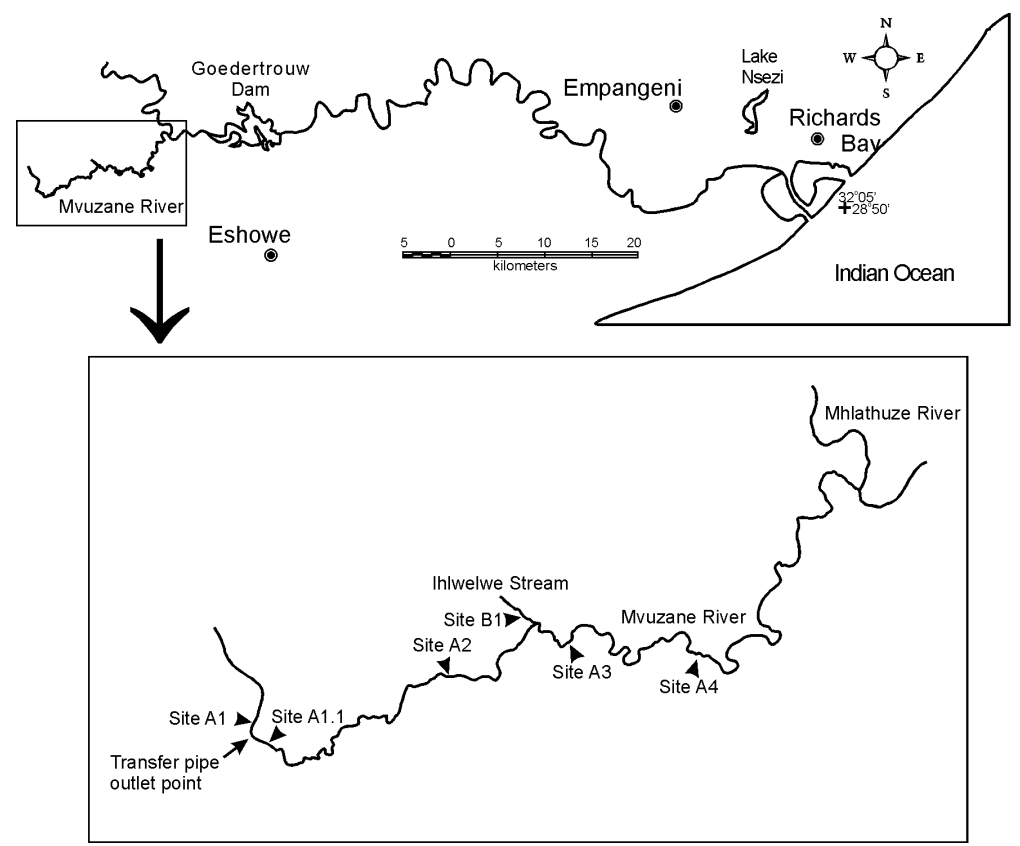

Figure 1

Map of study area showing site locations on the Mvuzane River

preserved separately in $4 \%$ formaldehyde solution and returned to the laboratory where invertebrates were removed from debris, identified to the taxonomic level of family and counted. Qualitative results (indices) were then determined for each site (biotopes combined) according to the SASS4 protocol (see Chutter, 1998).

The method followed here deviates from the standard procedure in that the SASS protocol makes no provision for laboratory analysis of samples. Rather, the sample is supposed to be analysed in the field for a prescribed period. Results expressed as modified SASS4 indices here may therefore be higher than what would have been the case if these indices had been derived in the field according to the protocol. This is not expected to influence the findings of this study. Although essentially a field-based technique the true test of operator proficiency is accurate identification of all taxa in a sample, and one of the methods of testing proficiency is to return field analysed samples to the laboratory for comparison.

SASS data output consists of two complementary matrices: SASS score (sum of taxon scores) and average score per taxon (ASPT, SASS4 score divided by the number of contributing families). Both are used in the assessment of water qual-

consequence many sections of the river are degraded, especially in terms of the riparian vegetation, and its geomorphological state has also been impacted upon by bad catchment management practices (IWR-E, 2000).

\section{Methods and materials}

Fieldwork was conducted in spring in 1999 (September) and 2000 (October). Five sites (A1, A2, A3, A4 and B1) were sampled fully for macroinvertebrates and in situ water quality parameters. Two were included as 'non-impact' or 'control' sites. Site A1 was sited on the Mvuzane immediately above the pumped water outflow pipe while B1 was located on the Ihlwelwe Stream, a small tributary in the catchment (Fig. 1). Neither of these sites was subject to the direct influence of any Thukela River water and any changes noted in their respective invertebrate assemblages could therefore not be directly attributed to the IBT. Physico-chemical parameters were recorded at the time of biological sampling and then at weekly intervals for a period of five weeks after the initial trip. A Hydrolab Datasonde 3 Water Quality Multiprobe was used and parameters measured in situ included temperature, dissolved oxygen content, $\mathrm{pH}$, conductivity and total dissolved solids. Turbidity samples returned to the laboratory were analysed using a Hach Model 2100A Turbidimeter. Discharges were determined by measuring flow velocities at points across the width of the river at each site with an Ott Flow Meter and applying a velocity-area method of discharge calculation.

The SASS4 methods of kick-sampling and sweep-netting different biotopes for prescribed times and areas were followed (net dimensions $300 \times 300 \mathrm{~mm}$ frame, $1 \mathrm{~mm}$ mesh; Chutter, 1998). Three biotopes occurred consistently and were sampled at each of the sites. They were open water sections with sand substrata, areas of marginal vegetation and stones-in-current. Depths were shallow, generally below $0.5 \mathrm{~m}$. At an additional site (Site A1.1) just below the outflow pipe (Fig. 1) only stonesin-current were sampled during pumping in 1999, but in 2000 all biotopes were sampled. Samples taken from each biotope were ity, but as habitat availability and condition also affects aquatic invertebrate assemblages it is necessary to link these matrices to a habitat assessment index. The Habitat Quality Index (HQI) as described in Thirion et al. (1995) was used in this study. This index, based on that of Plafkin et al. (1989), was originally developed as a rough habitat guide to complement SASS assessments. It relies on a subjective evaluation of several attributes of the river site sampled, including availability and quality of different habitat types, current speeds, bank erosion, cover and vegetation. MacMillan (1998) has pointed out that the reliance of the HQI on personal interpretation renders the index susceptible to variable scores amongst different operators, and in more recent years an alternative habitat assessment has been favoured. However, as all assessments during this study were made by the same operator comparisons of HQI between sampling trips were valid.

Broad ranges in indices have been defined to aid in the interpretation of SASS4 results for rivers in Mpumalanga (Thirion et al., 1995). However, no such categorisation has been developed regionally and for the purposes of this study modified SASS index scores from Site A1 in 2000 were assumed to indicate benchmark ecological conditions. Results from other sites in 2000, as well as those recorded during elevated flows in 1999, were expressed as percentages of these reference scores, and changes between years at the same site were reflected as differences in percentage reference score.

SASS5 (Dickens and Graham 2002) replaced SASS4 after this study had been completed. The minor modifications in taxon score designations were found not to alter the conclusions of this study. The reason for returning the samples to the laboratory was to allow for accurate counts of different taxa to be made. SASS indices rely on the presence or absence of certain invertebrate taxa rather than taking into account their absolute or relative abundance in a river reach. A more quantitative analysis might be needed to investigate assemblage changes and impacts upon the ecological integrity of the system. As SASS sampling methods were not considered to be sufficiently quantitative for the purpose in this study, total counts of different 


\begin{tabular}{|c|c|c|c|}
\hline \multicolumn{4}{|c|}{$\begin{array}{c}\text { TABLE } 1 \\
\text { Categorisation of invertebrates according to feeding strategies and modes of existence } \\
\text { [after Cummins (1996) and Davies and Day (1998)] }\end{array}$} \\
\hline \multicolumn{2}{|c|}{ Functional feeding group } & \multicolumn{2}{|c|}{ Mode of existence } \\
\hline Category & Description & Category & Description \\
\hline Shredders & $\begin{array}{l}\text { Herbivores, detritivores and chewers of coarse } \\
\text { particulate organic matter }\end{array}$ & Burrowers & $\begin{array}{l}\text { Inhabit sediments, some construct burrows or } \\
\text { may ingest their way through sediments }\end{array}$ \\
\hline Grazers & $\begin{array}{l}\text { Graze or browse algae, fungi and other micro- } \\
\text { organisms }\end{array}$ & Sprawlers & Crawl about on substrate surface \\
\hline $\begin{array}{l}\text { Collectors - } \\
\text { scrapers }\end{array}$ & $\begin{array}{l}\text { Sweep or scrape layers of bacteria, algae and } \\
\text { fungi off surfaces }\end{array}$ & Clingers & $\begin{array}{l}\text { Behavioural or morphological adaptations for } \\
\text { attachment to surfaces }\end{array}$ \\
\hline $\begin{array}{l}\text { Collectors - } \\
\text { gatherers }\end{array}$ & $\begin{array}{l}\text { Collectors of material flowing past in current } \\
\text { and deposit feeders, feed on fine particulate } \\
\text { organic matter }\end{array}$ & Climbers & $\begin{array}{l}\text { Adapted for living on aquatic macrophytes or } \\
\text { detrital debris (overhanging branches, roots and } \\
\text { vegetation) }\end{array}$ \\
\hline $\begin{array}{l}\text { Collectors - } \\
\text { filterers }\end{array}$ & $\begin{array}{l}\text { Possess filter or sieves of setae, or erect nets, } \\
\text { brushes, fans to trap fine particulate organic } \\
\text { matter }\end{array}$ & Swimmers & $\begin{array}{l}\text { Includes divers adapted for swimming by 'row- } \\
\text { ing' with hind legs }\end{array}$ \\
\hline Predators & $\begin{array}{l}\text { Carnivores that attack other fauna and feed by } \\
\text { engulfing or piercing }\end{array}$ & Skaters & Adapted for 'skating' on the water surface \\
\hline Other & $\begin{array}{l}\text { Where FFG unknown or could not be assigned, } \\
\text { dipteran pupae }\end{array}$ & Other & Where mode of existence could not be assigned \\
\hline
\end{tabular}

invertebrate families sampled could not be compared between sites, even within the same biotope. However, relative abundances could be determined for different taxa occurring at each biotope at a site. Thus the proportional contributions of categories of invertebrates could be determined and the stream communities from different biotopes could be described in terms of the predominant functional groups of invertebrates sampled. Changes in relative contributions of different functional feeding groups (FFGs) and guilds of taxa based on 'modes of existence' could then be investigated. The validity of such classification of invertebrates into functional groups, and especially into feeding guilds, has been debated (Allan, 1995; Davies and Day, 1998) but its application here is useful in attaining a broad synthesis of the ecological impacts of the transfer scheme. Categories as listed in Table 1 were assigned based on descriptions given by Cummins (1996) and Davies and Day (1998).

In a final broad overview of the implications of the transfer scheme comparisons of results from sites (column standardised to give relative abundances) from high- and natural-flow regimes were compared in terms of the extent to which they shared families at comparable levels of relative abundance. Hierarchical clustering (Bray-Curtis similarity coefficients) was performed on composite invertebrate assemblage data using the computer software package PRIMER (Plymouth Routines In Multivariate Ecological Research; Clarke and Warwick, 1994). Dividing each family count by total abundance of all taxa in a sample to express occurrence as relative abundance is essential when noncomparable, unknown sample volumes have been taken (Clarke and Warwick, 1994). Relative abundances here were expressed as percentages. Such standardisation does not remove the subsequent need to transform the data matrix, if the similarities are to take into account more than just the few commonest species (Clarke and Warwick, 1994), and data were subject to square root transformation before cluster analysis was performed.

\section{Results}

Rural settlement populations impacted upon habitat quality at all study sites to some degree by activities such as clothes-washing, bucket irrigation, small-scale subsistence and market-garden farming, and the watering and grazing of livestock. Land-use and resource utilisation did not appear to differ between sampling trips and the degree of anthropogenic impact was assumed to be unchanged. Revisiting the same locations during consecutive spring seasons therefore permitted direct comparison between sites, and accepting the assumption above, allowed the known differences in flow regimes and water characteristics to be inferred as causal in marked faunal changes that might be noted.

Flows at Site A1 (above transfer outflow) in 1999 and 2000 were similar at 0.014 and $0.020 \mathrm{~m}^{3} / \mathrm{s}$ respectively. However, flows differed markedly downstream of the transfer pipe outlet ranging from 0.220 to $0.710 \mathrm{~m}^{3} / \mathrm{s}$ during trial pumping in September 1999 but never exceeded $0.034 \mathrm{~m}^{3} / \mathrm{s}$ during natural flows in October 2000. River flows during pumping were generally about 20 times those during natural flow conditions at the same site. Physico-chemical parameters measured (Table 2) indicated that water quality during both sampling periods was not limiting to aquatic invertebrate fauna. Mann-Whitney Rank Sum Tests showed that at impact sites (A1.1, A2, A3 and A4) conductivity $($ T statistic $=849.5)$ and TDS $($ T statistic $=853.0)$ were significantly $(\mathrm{p}<0.05)$ higher during 1999 when the IBT was operational than in 2000 when it was not, while $\mathrm{pH}$ (T statistic $=300.0)$ and turbidity $(\mathrm{T}$ statistic $=395.0)$ were significantly lower. However, this was also true of control sites (A1 and B1, conductivity $\mathrm{T}$ statistic $=218.0$, TDS T statistic $=222.0, \mathrm{pH} \mathrm{T}$ statistic $=78.0$ and turbidity $\mathrm{T}$ statistic $=104.0$ ). No other variables were found to differ significantly between years sampled.

Habitat quality, in terms of HQI at least, was very similar at most sites during both sampling trips (Table 3 ). The noted exception was at Site A2 where HQI was higher during elevated flow in 1999 than during natural flow conditions in 2000. This was principally due to the deposition of river sand over a large area of the macro-channel at the site as a result of an episodic flood event during the months between sampling trips. In 2000, both banks were largely denuded of vegetation at the water's edge and a considerable amount of riffle and marginal vegetation habitat was lost. However, sufficient habitat of all biotopes remained available in 2000 for sampling to be considered consistent with that conducted in 1999.

Evidence of sediment accumulation after the transfer of water from the Thukela River had ceased was noted at all sites 


\begin{tabular}{|c|c|c|c|c|c|c|c|}
\hline Leve & $s(\mathrm{me}$ & standard e & $\begin{array}{l}\text { of physico-c } \\
\text { s (six weeks) }\end{array}$ & $\begin{array}{l}\text { TABLE } 2 \\
\text { mical parame } \\
\text { uring spring } 19\end{array}$ & $\begin{array}{r}\text { measured } \\
\text { and spring }\end{array}$ & mpling si & weekly inter- \\
\hline Year & Site & Temp $\left({ }^{\circ} \mathrm{C}\right)$ & $\begin{array}{c}\text { Conductivity } \\
(\mathrm{mS} / \mathrm{cm})\end{array}$ & $\begin{array}{c}\text { Dissolved } \\
\text { oxygen }(\mathrm{mg} / \mathrm{l})\end{array}$ & $\begin{array}{l}\text { TDS } \\
(\mathrm{mg} / \ell)\end{array}$ & PH & Turbidity (NTU) \\
\hline 1999 & A1 & $20.43 \pm 1.55$ & $0.36 \pm 0.01$ & $8.97 \pm 0.41$ & $0.23 \pm 0.01$ & $7.55 \pm 0.07$ & $4.28 \pm 0.37$ \\
\hline & A1.1 & $22.15 \pm 1.08$ & $0.45 \pm 0.02$ & $8.10 \pm 0.27$ & $0.29 \pm 0.01$ & $7.88 \pm 0.02$ & $16.57 \pm 2.40$ \\
\hline & A2 & $22.38 \pm 1.34$ & $0.45 \pm 0.02$ & $8.14 \pm 0.31$ & $0.29 \pm 0.02$ & $7.85 \pm 0.04$ & $24.90 \pm 3.34$ \\
\hline & A3 & $21.47 \pm 1.01$ & $0.45 \pm 0.02$ & $8.21 \pm 0.26$ & $0.29 \pm 0.02$ & $7.91 \pm 0.04$ & $23.93 \pm 4.45$ \\
\hline & A4 & $19.56 \pm 0.67$ & $0.46 \pm 0.02$ & $8.70 \pm 0.26$ & $0.29 \pm 0.02$ & $7.92 \pm 0.02$ & $17.10 \pm 2.45$ \\
\hline & B1 & $21.07 \pm 1.01$ & $0.31 \pm 0.01$ & $8.74 \pm 0.37$ & $0.22 \pm 0.01$ & $7.50 \pm 0.03$ & $13.33 \pm 1.05$ \\
\hline 2000 & A1 & $21.97 \pm 2.07$ & $0.25 \pm 0.01$ & $7.97 \pm 0.66$ & $0.16 \pm 0.01$ & $8.39 \pm 0.07$ & $15.90 \pm 1.95$ \\
\hline & A1.1 & $22.33 \pm 2.13$ & $0.27 \pm 0.01$ & $7.38 \pm 0.68$ & $0.17 \pm 0.01$ & $8.38 \pm 0.06$ & $21.15 \pm 3.84$ \\
\hline & A2 & $23.90 \pm 2.21$ & $0.33 \pm 0.02$ & $7.50 \pm 0.66$ & $0.20 \pm 0.02$ & $8.67 \pm 0.07$ & $51.08 \pm 10.64$ \\
\hline & A3 & $22.95 \pm 1.98$ & $0.33 \pm 0.01$ & $7.95 \pm 0.70$ & $0.20 \pm 0.01$ & $8.80 \pm 0.07$ & $62.43 \pm 10.91$ \\
\hline & A4 & $22.52 \pm 1.53$ & $0.31 \pm 0.03$ & $8.05 \pm 0.59$ & $0.21 \pm 0.01$ & $8.67 \pm 0.06$ & $60.12 \pm 15.21$ \\
\hline & B1 & $22.00 \pm 1.68$ & $0.23 \pm 0.01$ & $7.84 \pm 0.63$ & $0.14 \pm 0.01$ & $8.31 \pm 0.07$ & $65.82 \pm 11.55$ \\
\hline
\end{tabular}

TABLE 3

SASS4, ASPT and HQI indices as determined for sites during transfer flows in September 1999 and natural flows in October 2000. Number of taxa reported applies to families listed in the SASS4 protocol.

$\%$ ref $=$ percentage reference score (Site A1 in 2000), $\Delta \%$ ref $=$ difference $(2000-1999)$ in percentage reference score (1999 compared with 2000$)$, nd = no data.

\begin{tabular}{|c|c|c|c|c|c|c|c|c|c|c|c|c|}
\hline & \multicolumn{12}{|c|}{ Site } \\
\hline & \multicolumn{2}{|c|}{ A1 } & \multicolumn{2}{|c|}{ A1.1 } & \multicolumn{2}{|c|}{ A2 } & \multicolumn{2}{|c|}{ A3 } & \multicolumn{2}{|c|}{ A4 } & \multicolumn{2}{|c|}{ B1 } \\
\hline & 1999 & 2000 & 1999 & 2000 & 1999 & 2000 & 1999 & 2000 & 1999 & 2000 & 1999 & 2000 \\
\hline SASS4 & 199 & 236 & nd & 213 & 160 & 161 & 176 & 216 & 170 & 220 & 178 & 193 \\
\hline$\%$ ref & 84.32 & 100 & & 90.25 & 67.80 & 68.22 & 74.58 & 91.53 & 72.03 & 93.22 & 75.42 & 81.78 \\
\hline$\Delta \%$ ref & \multicolumn{2}{|c|}{-15.68} & \multicolumn{2}{|c|}{ nd } & \multicolumn{2}{|c|}{-0.42} & \multicolumn{2}{|c|}{-16.95} & \multicolumn{2}{|c|}{-21.19} & \multicolumn{2}{|c|}{-6.36} \\
\hline No. of taxa & 34 & 40 & nd & 35 & 26 & 26 & 29 & 38 & 30 & 39 & 32 & 33 \\
\hline$\%$ ref & 85.00 & 100 & nd & 87.50 & 65.00 & 65.00 & 72.50 & 95.00 & 75.00 & 97.50 & 80.00 & 82.50 \\
\hline$\Delta \%$ ref & \multicolumn{2}{|c|}{-15.00} & \multicolumn{2}{|c|}{ nd } & \multicolumn{2}{|c|}{0.00} & \multicolumn{2}{|c|}{-22.50} & \multicolumn{2}{|c|}{-22.50} & \multicolumn{2}{|c|}{-2.50} \\
\hline ASPT & 5.85 & 5.90 & nd & 6.09 & 6.15 & 6.19 & 6.07 & 5.68 & 5.67 & 5.64 & 5.56 & 5.85 \\
\hline$\%$ ref & 99.20 & 100 & & 103.15 & 104.30 & 104.95 & 102.86 & 96.34 & 96.05 & 95.61 & 94.28 & 99.13 \\
\hline$\Delta \%$ ref & \multicolumn{2}{|c|}{-0.80} & \multicolumn{2}{|c|}{ nd } & \multicolumn{2}{|c|}{-0.65} & \multicolumn{2}{|c|}{+6.52} & \multicolumn{2}{|c|}{+0.43} & \multicolumn{2}{|c|}{-4.85} \\
\hline HQI & 88 & 86 & nd & 85 & 80 & 55 & 86 & 85 & 90 & 96 & 90 & 90 \\
\hline$\%$ ref & 102.33 & 100 & nd & 98.84 & 93.02 & 63.95 & 100.00 & 98.84 & 104.65 & 111.63 & 104.65 & 104.65 \\
\hline$\Delta \%$ ref & \multicolumn{2}{|c|}{+2.33} & \multicolumn{2}{|c|}{ nd } & \multicolumn{2}{|c|}{+29.07} & \multicolumn{2}{|c|}{+1.16} & \multicolumn{2}{|c|}{-6.98} & \multicolumn{2}{|c|}{0.00} \\
\hline
\end{tabular}

on the Mvuzane downstream of the transfer outflow. A greater percentage of the streambed during transfer flows comprised course gravels, cobbles and rocks than during natural flows. Nevertheless, a sufficient area of each major biotope was always found within reaches of $100 \mathrm{~m}$ delimiting each site and there was generally a good variety of habitat types, including boulders, rocks and sand, at all sites during both years. There was a consistent lack of emergent and submerged macrophytes but marginal vegetation was present in the form of non-aquatic grasses overhanging on the banks and trailing in the stream water.

Rapid bioassessment indices in the form of composite scores, derived by grouping family occurrences from each biotope, are given in Table 3. Each taxon was scored only once regardless of whether it occurred in more than one biotope. Highest SASS4 scores and numbers of taxa were attained at the control Site A1. In 2000 Site A2 (with the lowest HQI) had the lowest SASS4 score but rather surprisingly had the highest ASPT suggesting that habitat quality rather than water quality was limiting.

SASS4 scores were lower at all sites, including control sites, in September 1999 than October 2000. The most marked differ- ences were noted at Sites A3 and A4 where scores, expressed as a percentage of the reference value were approximately 17 and $21 \%$ respectively lower during prolonged elevated flows than during natural flows (Table 3). However, control sites (especially Site A1) also yielded lower SASS scores during 2000. On average relative SASS scores at IBT sites (A2, A3, A4) were 13.5\% lower during IBT flows, whilst those at control sites (A1, B1) were $9.8 \%$ lower. ASPT differed only slightly between periods. As percentages of the reference values, ASPTs at impact sites during IBT flows were on average $1.1 \%$ above those during natural flows, whilst those at control sites were on average $0.8 \%$ lower. This indicated that higher SASS4 scores during 2000 were the result of higher numbers of taxa rather than more sensitive organisms, and suggested that the fauna at IBT sites did not change markedly more than that at control sites despite significant differences between flows during different years. These data were analysed in more detail.

Eight taxa sampled at Site A1 in 2000 were not recorded in 1999. Five of these occurred as single representatives and a $6^{\text {th }}$ was represented by only two specimens. Corixidae was 


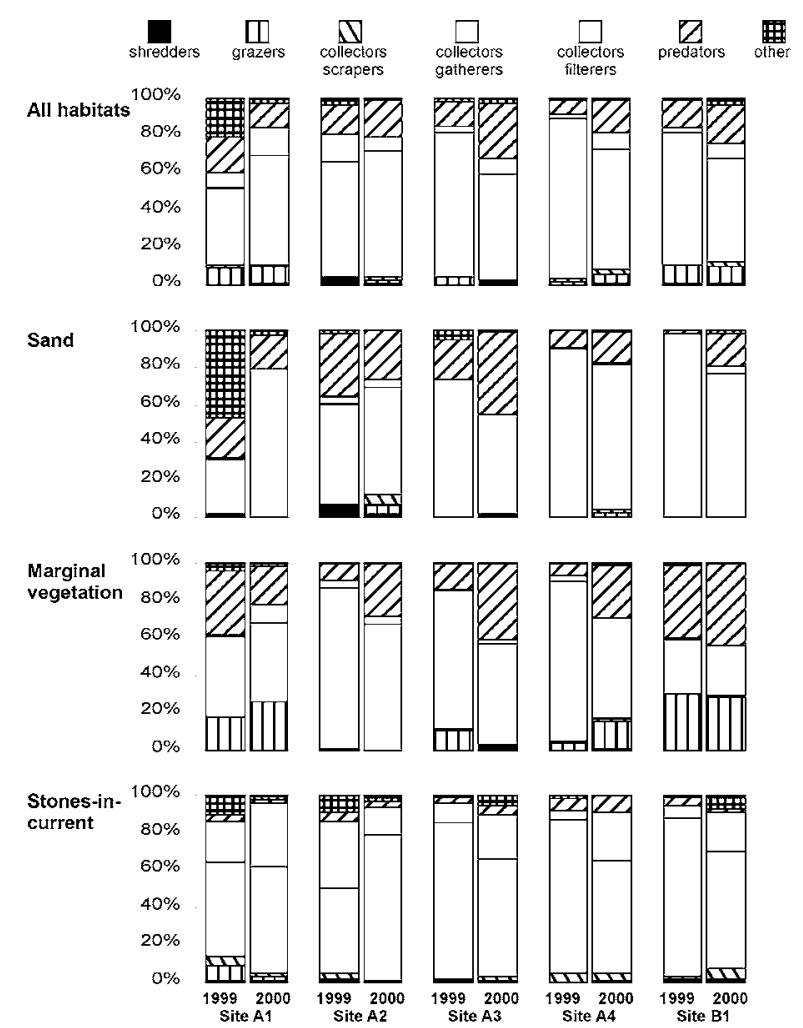

Figure 2

Percentage contribution of different functional feeding groups of invertebrate fauna sampled from three different biotopes at control- and IBT sites

the only family absent in 1999 to occur in notable numbers and contributed a significant percent of the animals sampled in 2000 (especially over open sand-bed). Two taxa sampled in 1999 were not recorded in 2000. The increased SASS4 score at Site A1 in 2000 was therefore brought about largely by the occurrence of extra taxa in very low numbers (in most cases single specimens). There was little change in the relative abundance of different functional feeding groups (FFGs) between years except over open sand (Fig. 2). The assemblage in this biotope in 1999 had a lower percentage of 'gatherers' than in 2000 , mainly due to a much reduced contribution of Chironomidae larvae and Oligochaeta. There were, however, relatively many more Chironomidae pupae in sand-bed biotope in 1999 than in 2000. For the purposes of FFG analysis chironomids at the pupal stage were classified under 'other'. In terms of the modes of existence there was also little change in relative contributions to the invertebrate assemblage. There was a higher contribution of 'swimmers' and 'skaters' in 1999 than in 2000, due most notably to the high abundance of Chironomidae pupae over open sand substrate (Fig. 3).

At Site A1.1 only stones-in-current were sampled in both 1999 and 2000 and discussion is limited to this biotope. In 1999 only 12 taxa were sampled immediately below the inflow of transferred water, and five of these were as single animals. Less than $100 \mathrm{~m}$ above the inflow at Site A1 on the same day, invertebrates from stones-in-current were much more abundant and 26 different taxa were sampled. This suggested that the inflow of transfer water was causal in the depauperate fauna noted below the outlet. In 2000, under conditions of natural flow, 20 taxa were recorded below the dry transfer-pipe outlet in stones-in-current (none as single occurrences) and little change in species composition between assemblages at Sites A1 and A1.1 was noted. It can therefore be deduced

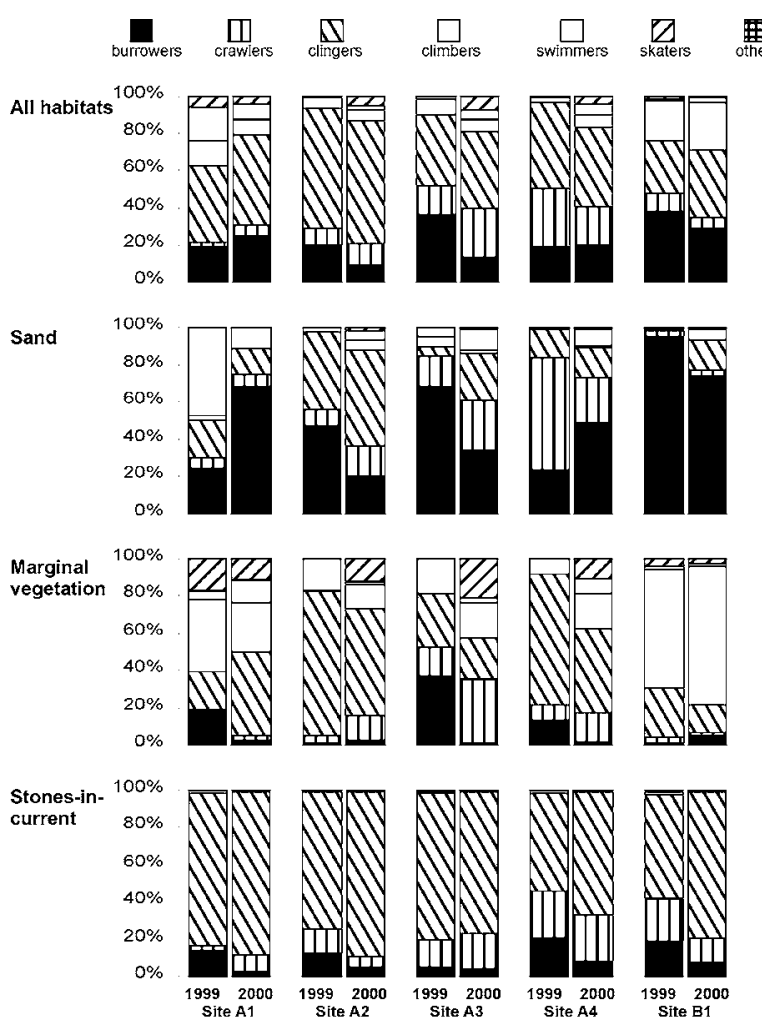

Figure 3

Percentage contribution of different categories of invertebrate fauna (based on mode of existence) sampled from three different biotopes at control- and IBT sites

that the low diversity noted below the inflow in 1999 was a direct result of the transfer scheme and that recovery of invertebrate fauna from this impact occurred within ten months.

There was little apparent change in SASS4 or ASPT indices at Site A2 between years (Table 3). Species numbers remained the same and changes in taxa occurring were minor. Naucoridae were sampled in 2000 but not in 1999 and there was a substantial increase in the number of Veliidae sampled during natural flow conditions. These groups made notable contributions to the fauna sampled over sand and in marginal vegetation in 2000 . Relative abundance of planaria and prawns were reduced during natural flows compared with elevated transfer flows. Contributions of various FFGs during the two sample periods were similar in all biotopes except in stones-in-current where there were relatively fewer 'gatherers' and more 'filterers' during high flow (1999) than natural flow (2000) (Fig. 2). A higher percentage of 'swimmers' and 'skaters' and relatively fewer 'burrowers' were present in 2000 (Fig. 3).

Higher SASS4 scores were recorded at Site A3 in 2000 than in 1999, due to markedly more taxa being sampled. However, of the 13 taxa sampled in 2000 but not in 1999 three were as single individuals and another four were found in low numbers (less than five individuals). Four taxa were recorded in 1999 but not in 2000, all also in numbers of below five individuals. Taxa present in large numbers in 2000 but absent in 1999 were Veliidae and Naucoridae, and to a much lesser degree Belastomaidae and Gerridae. All of these taxa are 'predators' and are either 'swimmers' or 'skaters'. They were sampled most abundantly in marginal vegetation. In 2000 over $30 \%$ of the invertebrates sampled at Site A3 were 'predators' and over 12\% were 'swimmers' and 'skaters' compared to less than $15 \%$ and 2\% respectively in 1999 (Figs. 2 and 3). The changes in relative contributions of different 


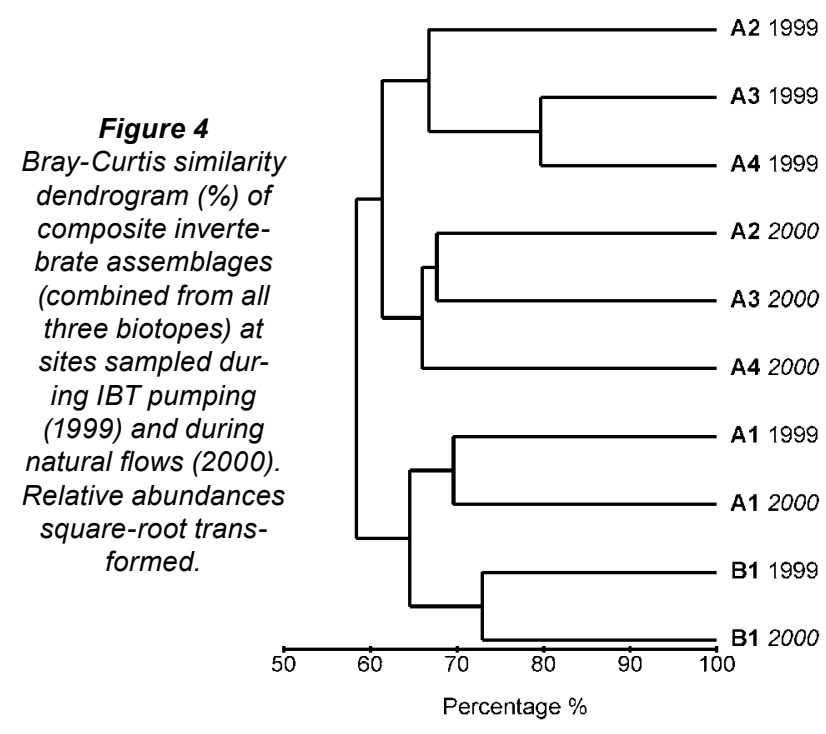

FFGs and groups based on mode of existence were most pronounced in marginal vegetation with increased proportions of these groups at the expense of 'grazers' and 'gatherers' (FFGs) and 'burrowers' (habit category). There were also relatively more 'predators' and fewer 'burrowers' over sand biotope during natural flows in 2000 than during elevated flows in 1999.

A higher number of taxa (rather than the presence of higher scoring taxa) was also the reason for an increased SASS4 score at Site A4 in 2000 compared with 1999. Twelve taxa sampled in 2000 were not present in 1999 while only three sampled in 1999 were not present in 2000. Of the latter group only Empididae were recorded in abundances greater than 5 animals and even then they comprised only $1 \%$ the total number of invertebrates sampled. As was the case at Site A3, taxa occurring in 2000 but absent in 1999 were mostly 'swimmers' and 'skaters' (Veliidae, Corixidae, Naucoridae and Dytiscidae). Belastomatidae, present as a single individual in 1999, were much more plentiful in the marginal vegetation in 2000. As at Site A3, Tricorythidae made a significant contribution to invertebrates in stones-in-current in 2000 after being absent in the higher flows in 1999. This resulted in increased proportions of 'filterers' in stones-in-current. There were relatively fewer 'gatherers' and more 'predators' during natural flows than elevated flows (Figs. 2 and 3).

There was little change in SASS4 score or number of recorded taxa at Site B1. Seven taxa recorded in low percentages 1999 at Site B1 were absent in 2000. Eight taxa recorded in 2000 were not sampled in 1999. Four of these occurred as single individuals and only planaria contributed more than $5 \%$ to the invertebrates sampled in any one biotope (7.7\% in stones-in-current). Oligochaetes and Chironomidae larvae, although present in both years, were markedly reduced in numbers and percentage abundance in 2000, particularly in open sand biotope. This reduced the relative contribution of 'burrowers' and 'gatherers' in this biotope (Fig. 2).

In comparing invertebrate faunas sampled from different biotopes at sites in 1999 and 2000 generalised trends were observed based on relative contributions of families and faunal groups. Least change was observed in assemblages sampled from stones-in-current (Figs. 2 and 3). In marginal vegetation there were consistently more 'swimmers' and 'skaters' (comprising predaceous families) at Sites A2, A3 and A4 in 2000 than 1999. This was not true of the control Sites A1 and B1. It was also apparent that 'clingers' present in the marginal vegetation during high flows were replaced by 'crawlers' during natu- ral flow conditions. This was also evident to a lesser degree over the open sand-bed biotope (Fig. 3).

Results from cluster analysis of composite assemblage data indicated distinct clusters of relatively similar invertebrate communities from sites sampled during transfer and natural flow conditions in 1999 and 2000 in the Mvuzane River and Ihlwelwe Stream (Fig. 4). Control sites, unaffected by the transfer scheme, supported communities that remained similar over the years studied. Although located on different streams these sites were also more similar to one another than any others on the Mvuzane River. On the other hand samples taken from the Mvuzane River below the transfer outflow were more similar within years (and flow conditions) rather than amongst locations (Fig. 4). Thus it appears that control sites remained relatively unchanged whilst the others responded similarly to the influence of an aseasonal and prolonged augmentation of flow. No single taxon or group of taxa was overwhelmingly responsible for the observed grouping of 'impacted' sites compared with 'unimpacted' sites. However, analysis of contributions to the similarities observed indicated the average relative reductions during natural flows in Oligochaeta and Leptophlebiidae, and increases in Veliidae and Naucoridae to be important. The reduction in oligochaetes was most noted at Site A3 where they were sampled in 1999 in abundance from a pool and contributed over $27 \%$ to the total number of animals sampled. In 2000 they contributed on average less than $1 \%$ of all animals sampled at Site A3. Leptophlebiidae were consistently reduced in relative abundance at Sites A2, A3 and A4 in 2000 compared with 1999. Veliidae and Naucoridae were not recorded at these sites in 1999 but were found, in roughly similar percentages, in 2000 .

\section{Discussion}

Davies et al. (1992) have argued against including the criterion of a minimum volume or flow to define an inter-basin water transfer, pointing out that doing so allows for no consideration of the relative natural flow of the receiving stream. This point is well illustrated here. Even at half capacity with only one pump train operational $\left(0.6 \mathrm{~m}^{3} / \mathrm{s}\right)$ transfer flows from the Thukela River to the Mvuzane River completely dominate natural flows and markedly change the natural hydrological regime of the recipient system. Given that the operating rules are to be driven by percentage fullness of the Goedertrouw Dam it can be expected that augmentation flows will be aseasonal. Lowest natural flows in the Mhlathuze River in winter coincide with highest water demands from the dam and therefore higher volumes of water will be transferred via the Mvuzane River during the normally dry period. Such shifts in flow regimes are common to interbasin transfers, as are changes in the water chemistries of recipient systems. From different countries and regions across the world these changes have been shown to impact negatively upon aquatic biota (Davies et al., 1992).

By monitoring during the same season and making comparisons between specific sites with similar biotope availability, the potential influences of longitudinal changes, seasonal variability and biotope availability on SASS4 measurements, as illustrated by Dallas (1997), were avoided in this study. SASS4 assessment indicated that water quality was good and that no significant change from this broad categorisation was brought about due to the transfer of water from the Thukela River as pumped during 1999. During pumping biological indices were generally lower than during conditions of natural flow but this was noted at control sites as well as those potentially impacted upon by the transfer scheme. As samples were analysed in the laboratory SASS scores 
may have been artificially high, but it was apparent that biota relatively sensitive to water quality were found at all sites, even during transfer flow conditions. SASS monitoring will therefore be useful as a rapid, field-based assessment of water quality and as acting as a 'red flag' to problems in the future. Control sites were found to be consistent (over this limited study period) in the biota that they supported and should be retained in any ongoing monitoring programme in order that the cause of potential future impacts on water quality be confidently isolated.

Rapid biological assessment, however, proved inefficient in investigating the wider ecological impacts of the transfer scheme. SASS indices were not sensitive to changes in the community structure at different sites. Higher scores at control sites during natural flow were often brought about by additional families sampled in very low abundances whilst those at other sites often involved new families occurring in substantial numbers. Furthermore changes in relative contributions of families that were found during both sampling trips were most marked at sites on the Mvuzane River downstream of the transfer scheme flow outlet. This was not reflected in SASS4 or ASPT scores, both of which rely upon presence/absence data. The application of SASS5 scoring criteria did not change this finding. Thus caution should be exercised in using the rapid biomonitoring indices as indicators of flow modification and measures of ecological integrity. The sampling protocols are only crudely quantitative and indices rely on the presence or absence of certain invertebrate taxa rather than taking into account absolute or relative abundances of all taxa occurring in a river reach. The use of such rapid assessment approaches is analogous to using thermometers to assess human health (Resh and Jackson, 1993).

Impacts upon community structure due to increased flows in streams and rivers are to be expected and occur naturally during floods. Increased friction, drag and lift negatively affect bluntly shaped and slow-moving taxa. Dorso-ventrally flattened animals that inhabit the boundary layer avoid these forces but they may be subject to dislodgment and/or crushing due to increased sediment movement caused by high flows. In the case presented here of the Mvuzane River elevated flows were prolonged and differences in relative abundances of groups of invertebrates reported were consistent with those that would be expected. 'Swimmers' and 'skaters' decreased because they could not maintain their positions and were swept away by the increased current. Similarly, fewer 'crawlers' made use of marginal vegetation during high flows and were replaced by 'clingers'. Alternatively, increased current speeds may have reduced food resources of these groups and effects may have manifested via interrupted trophic pathways. Although moving water has long been known to control the distribution of invertebrates in streams, Doisy and Rabeni (2001) cite confounding reports and their own inconclusive findings relating to the direct influence of flow conditions and the indirect effects on food resources of aquatic invertebrates. Changes most notable in the trophic structure of assemblages during this study were reductions in the proportion of predators from sand and marginal vegetation. However, taxa involved most often comprised 'swimmers' and 'skaters' and the primary impact on these groups was most plausibly one of high flow on their modes of existence as discussed above. Trophic changes were therefore only indirectly attributable to the transfer scheme. However, over a longer period changes in the trophic dynamics will almost certainly result from the transfer scheme. Even disregarding the possible effects due to different water chemistry, enhanced flow will influence exchange fluxes of organic matter between the sediments and the water column. Rivers are often described as spiralling their nutrients down their lengths rather than cycling them and flow velocity is clearly one of the determinants of spiralling distance (Allan, 1995). Davies and Day (1998) have suggested that during seasonal low-flow periods nodes may also develop where localised nutrient cycling may occur, and that spates are important in bringing about groundwater infiltration and upwelling through the streambed to release rich nutrient resources into the water column. Prolonged high flows, especially those that are aseasonal, will therefore profoundly affect nutrient dynamics in the Mvuzane River over time.

Of the 3 biotopes consistently sampled down the course of the Mvuzane River stones-in-current supported functional groups that were apparently least affected by the transfer flows. This biotope generally only occurs in reaches of swifter water and supports appropriately adapted fauna. Thus groups of invertebrates in this biotope were more predisposed to swifter flows and erosional habitat than those sampled elsewhere and were understandably least affected by elevated transfer flows. However, within these broad functional categories relative abundances of different families did change suggesting taxon-specific responses to high flow disturbance. This would have been even more pronounced at the level of species. The implications of such changes have, in some cases, been found to extend beyond the banks of the river. For example, an inter-basin transfer from the Orange to the Fish River resulted in the dominant species of simuliids being replaced by a different simuliid species, which was a blood-feeding pest of livestock (O'Keeffe and De Moor, 1988).

Although limitations in the universal application of the river continuum concept (Vannote et al., 1980) are now well recognised, biological changes along a river's course are an acknowledged fact and it is clear that rivers do function as longitudinal units (Allan, 1995; Davies and Day, 1998). The stretch of river sampled in this study was relatively short but changes in section gradients and the nature of different sites would be expected to dictate invertebrate fauna within seasonal constraints. This was found to be the case at control sites but the overriding influence at all other sites appeared to be that of inter-basin transfer flow. This transfer from the Thukela River undoubtedly changed physico-chemical properties of the Mvuzane River water. However, the primary impact on the invertebrate fauna was one of increased flow volumes and velocities on modes of existence of different taxa. The influence therefore, was one of change in water quantity rather than water quality. The inability of SASS to reflect this change is important. This rapid bioassessment technique is presently used in the determination of instream flow requirements in the description of reference conditions and ecological management classes and in the setting of ecological specifications and thresholds of potential concern. Although the methodology does allow for some elaboration and description this study indicates that in some cases at least, SASS is insensitive to marked changes in flow regime and does not respond to ecological impact in rivers.

As noted previously, disturbance of stream communities by spates in discharge is a natural phenomenon. Many species have the ability to resist such floods through the temporary use of refugia, for example, or to recolonise in numbers after the disturbance (Power et al., 1988). In fact spates and floods are important to the life histories and functioning of some aquatic organisms and communities (Lowe-McConnell, 1988; Welcomme, 1988). In this study, however, elevated flows brought about by trial pumping were prolonged and impacted upon the invertebrate faunal composition. Ten months after the system had been returned to natural flows the biota had changed, presumably at least partially recovering to the system's natural equilibrium. Disturbance and 
shifts in this equilibrium will be unavoidable once the transfer scheme is fully operational. Predicting the degree of future impacts, their significance and acceptability is the next issue that needs to be addressed. This will determine the extent to which mitigation measures should be implemented. These will involve taking ecological issues into consideration in compiling a set of operational rules for pumping. Seasonal periodicities in factors, including flow, often act as a cue for migration, breeding and emergence, and also influence feeding and growth in many taxa (Dallas, 1997). In the Mvuzane River winter is the season with lowest and least variable flow under natural conditions, but it is potentially the season when water will be transferred most consistently and at the highest rates. Changes in hydrological regime are therefore going to be most marked in the dry season, but these will affect river ecology year round.

The significance of future impact may be gauged based on the expected degree of impact and an assessment of the occurrence and status (present and future) of representative catchments nearby that are similar to the Mvuzane catchment. This will place into perspective the value of mitigating and managing the Mvuzane River within confines of an ecological class based largely on the system as it occurred naturally in an unimpacted state. Steedman (1994), in discussing the concept of ecosystem health, followed Karr (1991; 1995) in using ecological 'integrity' to refer to the condition at sites with little or no influence from human actions and having a resident biota representative of evolutionary and biogeographic processes. In contrast, 'health' was used to describe the preferred state of sites modified by human activities. If the abiotic and biotic natures of the Mvuzane River catchment are found to be regionally unique (confirmation of which will necessitate species level identification) then ecological integrity, in its strictest sense, will be a desirable management goal and stringent mitigation measures will need to be enforced. However, if they are found to occur commonly in similar small catchments it may be acceptable (and even prudent in an area where most rivers are negatively impacted by reductions in flow) to accept modifications in habitat and ecological functioning, and to manage flows in a manner that allows at least rheophilic fauna to take advantage of the excess water.

\section{Acknowledgements}

This work was carried out for IWR Environmental, as consultants to Mhlathuze Water Amanzi, as part of a greater study investigating ecological and social aspects of the IBT. Both organisations are thanked for approval to publish the findings. Dr Roy Wadeson of IWR Environmental is thanked for the flow data and the assistance of members of CRUZ in the field is gratefully acknowledged.

\section{References}

ALLAN JD (1995) Stream Ecology: Structure and Function of Running Waters. Chapman and Hall, London, UK. 388 pp.

CHUTTER FM (1998) Research on the Rapid Biological Assessment of Water Quality Impacts in Streams and Rivers. WRC Report No. 422/1/98. Water Research Commission, Pretoria, South Africa.

CLARKE KR and WARWICK RM (1994) Change in Marine Communities: An Approach to Statistical Analysis and Interpretation. Plymouth Marine Laboratory, Plymouth, UK. 144 pp.

CUMMINS KW (1996) Ecology and distribution of aquatic insects. In: Merritt RW and Cummins KW (eds.) An Introduction to the Aquatic Insects of North America ( $3^{\text {rd }}$ edn.). Kendall/Hunt Publishing Company. Dubuque. $862 \mathrm{pp}$.
DALLAS HF (1997) A preliminary evaluation of aspects of SASS (South African Scoring System) for the rapid bioassessment of water quality in rivers, with particular reference to the incorporation of SASS in a national biomonitoring programme. Sth. Afr. J. Aquat. Sci. 23 (1) 79-94.

DAVIES B and DAY J (1998) Vanishing Waters. UCT Press, Cape Town, South Africa. 487pp.

DAVIES BR, THOMS M and MEADOR M (1992) An assessment of the ecological impacts of inter-basin water transfers, and their threats to river basin integrity and conservation. Aquat. Conserv: Mar. Freshwater Ecosyst. 2 325-349.

DEPARTMENT OF WATER AFFAIRS AND FORESTRY (1996) South African Water Quality Guidelines. Volume 7: Aquatic ecosystems.

DICKENS CWS and GRAHAM PM (2002) The South African Scoring System (SASS) Version 5 Rapid Bioassessment Method for Rivers. Afr. J. Aquat. Sci. 27 1-10.

DOISY K and CF RABENI (2001) Flow conditions, benthic food resources, and invertebrate community composition in a low-gradient stream in Missouri. J. N. Am. Benthol. Soc. 20 (1) 17-32.

IWR-E (2000) Thukela Mhlathuze Emergency Transfer: Environmental Baseline Study Mvuzane Stream. Report prepared for Mhlathuze Water Amanzi. IWR Environmental, unpublished report.

KARR JR (1991) Biological integrity: a long-neglected aspect of water resource management. Ecol. Appl. 1 66-84.

KARR JR (1995) Ecological integrity and ecological health are not the same. In: Schulze P (ed.) Engineering within Ecological Constraints. National Academy of Engineering, National Academy of Science, Washington, D.C.

MACMILLAN PH (1998) An Integrated Habitat Assessment System (IHAS v2), for the Rapid Biological Assessment of Rivers and Streams. CSIR Research Project, ENV-P-I 98132 for the Water Resources Management Programme, CSIR, Pretoria, South Africa. Ii? +44 pp.

O'KEEFFE JH and DE MOOR FC (1988) Changes in the physicochemistry and benthic invertebrates of the Great Fish River, South Africa, following an interbasin transfer of water. Regulated Rivers: Res. Manage. 2 39-55.

PLAFKIN JL, BARBOUR MT, PORTER KD, GROSS SK and HUGHES RM (1989) Rapid Bioassessment Protocols for Use in Streams and Rivers: Benthic Macroinvertebrates and Fish. United States Environmental Protection Agency Report No. EPA/444/4-89-001. Assessment and Watershed Division, Washington, DC.

LOWE-MCCONNELL RH (1988) Concluding remarks II: Tropical perspective for future research in river ecology. J. N. Am. Benthol. Soc. 7 (4) 527-529.

POWER ME, STOUT, RJ, CUSHING CE, HARPER PP, HAUER FR, MATTHEWS WJ, MOYLE PB, STATZNER B and WAIS DE BADGEN IR (1988) Biotic and abiotic controls in river and stream communities. J. N. Am. Benthol. Soc. 7 (4) 456-479.

RESH VH, BROWN AV, COVICH AP, GURTZ ME, LI HW, MINSHALL GW, REICE SR, SHELDON AL, WALLACE JB and RC WISSAR (1988) The role of disturbance in stream ecology. J. N. Am. Benthol. Soc. 7 (4) 433-455.

RESH VH and JACKSON JK (1993) Rapid assessment approaches to biomonitoring using benthic macroinvertebrates. In: Rosenberg DM and Resh VH (eds.) Freshwater Biomonitoring and Benthic Macroinvertebrates. Chapman and Hall, New York, USA. 195-233.

STEEDMAN RJ (1994). Ecosystem health as a management goal. $J . N$. Am. Benthol. Soc. 13 (4) 605-610.

THIRION C, MOCKE A and R WOEST (1995) Biological Monitoring of Streams and Rivers using SASS4: A User Manual. Institute for Water Quality Studies Report No. N0000/00/REQ/1195. Department of Water Affairs and Forestry, Pretoria, South Africa. 46 pp.

VANNOTE RL, MINSHALL GW, CUMMINS KW, SEDELL JR and CE CUSHING (1980) The river continuum concept. Can. J. Fish. Aquat. Sci. 37 130-137.

WELCOMME RL (1988) Concluding remarks I: On the nature of large tropical rivers, floodplains, and future research directions. J. N. Am. Benthol. Soc. 7 (4) 525-526. 